\title{
Best Paper Awards for 2016
}

During 2013, Birkhäuser (Springer) instituted three Best Paper Awards for papers published in Circuits, Systems and Signal Processing (see the announcement in the October 2013 issue of CSSP). A call for nominations for these awards was sent out to all the Associate Editors inviting them to nominate those papers published in 2015 or 2016 in CSSP, which should be considered for these awards. This call was also posted on the CSSP Web site. A total of seven papers were nominated. A Selection Committee consisting of Dr. Robert W. Newcomb of University of Maryland, USA, Dr. P. V. Ananda Mohan, Electronic Corporation of India Limited, Bangalore, India; Dr. Ahmed M. Soliman of Cairo University, Egypt; and Dr. Vinod A. Prasad, Indian Institute of Technology, Palakkad, India, was set up to select the best paper in each category for the year 2016. The recipients for the Armen H. Zemanian Best Paper Award, given for the best paper published in 2016 in the areas of Circuits and Systems, are Gabriel Harja, Ioana Nascu, Cristina Muresan, and Ioan Nascu for their paper entitled "Improvements in Dissolved Oxygen Control of an Activated Sludge Wastewater Treatment Process", published in the June 2016 issue, pp. 2259-2281. The recipient for the Sydney R. Parker Best Paper Award, given for the best paper published in 2016 in the area of Signal Processing, is Pramod K. Meher for his paper entitled "Seamless Pipelining of DSP Circuits", published in the April 2016 issue, pp. 1147-1162. The former paper was also chosen for the M. N. S. Swamy Best Paper Award, which is given for the best paper published in 2015 or 2016 irrespective of the subject area. Each of these awardees will receive a certificate and a cash prize. I would like to congratulate the recipients of the three awards. I would also like to take this opportunity to thank all the nominators and especially, the members of Selection Committee for their time and effort in selecting the winners for the various awards.

M. N. S. Swamy Editor-in-Chief, CSSP 